\title{
Liberalismo e democracia na Sociologia Política de Oliveira Vianna
}

RICARDO SILVA*

\section{Resumo}

0 artigo examina o pensamento político de Oliveira Vianna, por meio de um diálogo crítico, com modelo de interpretação que define como "autoritarismo instrumental" a singularidade de sua concepção de Estado. Em tal modelo de interpretação, as instituições do Estado autoritário idealizadas e propostas pelo sociólogo fluminense são apresentadas como instrumentos (meios) adequados para a realização do liberalismo político e da democracia no Brasil. U ma vez atingidos seus verdadeiros fins liberais e democráticos, o caráter autoritário do Estado poderia ser questionado e abolido. Em nosso entender, além de não questionar o equivocado pressuposto de que é possível a realização de fins democráticos por meios autoritários, o modelo do "autoritarismo instrumental" é inapropriado para a compreensão, dimensão ideológica do pensamento político de O liveira Vianna, orientada para a justificação de uma forma de Estado antiliberal e antidemocrática.

Palavras-chave: O liveira Vianna. Democracia. Liberalismo. Autoritarismo. Pensamento social brasileiro.

* D outor em Ciências Sociais pela U niversidade Estadual de Campinas (U N ICAM P) e Professor do Programa de Pós-graduação em Sociologia Política da Universidade Federal de Santa Cararina (UFSC) < rsilva@ cfh.ufsc.br> 


\section{Introdução}

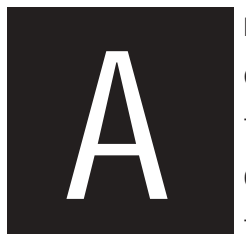

riqueza dos textos de determinados pensadores pode ser, em parte, dimensionada pela recorrência das diversas interpretações que são capazes de suscitar. Conforme bem observou Bobbio, uma das principais características dos textos clássicos consiste no fato de que são recorrentemente tomados como objetos de "releituras e reinterpretações", uma vez que nos oferecem "teorias-modelo das quais nos servimos continuamente para compreender a realidade" (BO BBIO, 2000, p. 131).

É verdade que, com o passar do tempo, os textos clássicos distanciamse dos problemas imediatos que procuravam responder e das intenções originais de seus autores ao os terem escrito (RICOEUR, 1979). Mas, por outro lado, ressurgem revitalizados no trabalho crítico de seus intérpretes. Assim, para fins de dimensionamento da contribuição de um pensador clássico, o exame das diferentes interpretações de sua obra não é algo que possa ser desprezado; ao contrário, é parte fundamental das tarefas de elucidação dos sentidos que esta obra adquire em diferentes momentos históricos e da avaliação de suas eventuais potencialidades cognitivas para o estudo do presente.

$\mathrm{Na}$ história do pensamento político brasileiro do século XX, poucos autores têm reunido tão amplamente as condições justificativas do qualificativo de "clássico" do que o sociólogo e historiador fluminense Francisco José O liveira Vianna. Suas idéias tiveram impacto quando originalmente difundidas e revelaram persistência em épocas seguintes, constituindo-se, até os dias atuais, em objeto da atenção de historiadores das idéias e cientistas sociais das mais diversas orientações.

Q uando nos deparamos com a tarefa de interpretar as idéias de O liveira Vianna, a primeira dificuldade que surge relaciona-se à extensão, ao 
volume e aos diversos planos de sua obra. Para tornar a tarefa viável, é necessário selecionarmos o foco de nossas preocupações em relação ao imenso conjunto de textos que constitui seu legado.

Nos limites deste artigo, pretendemos focalizar a dimensão políticoinstitucional do pensamento de O liveira Vianna, voltando a atenção para o exame de suas reflexões sobre as instituições estatais no Brasil, quer em seu registro analítico, quer no plano normativo. Em outros termos, buscaremos elementos para tentar responder a seguinte questão: Considerando sua análise da gênese e do desenvolvimento das instituições políticas brasileiras, bem como as sugestões de reformas institucionais amiúde apresentadas em seus livros, 0 que se pode depreender a propósito da natureza da forma de Estado considerada pelo autor como a mais apropriada à formação social brasileira?

\section{A Crítica ao Constitucionalismo Liberal}

O bjetivando responder a questão formulada acima, realizaremosum diálogo crítico com uma influente linha de interpretação do pensamento político de O liveira Vianna, a qual tem sido desposada por inúmeros analistas do pensamento social e político brasileiro (SANTOS, 1978; MORAES, 1986 e 1993; PAIM , 1987 e BASTOS 1993). Trata-se da interpretação que apresenta como um tipo de "autoritarismo instrumental" a especificidade da concepção de Estado, que organiza o pensamento político de nosso autor. $\mathrm{O}$ u seja, as instituições do Estado autoritário, elaboradase justificadas em diferentes momentos de sua obra, são compreendidas como "meios" (ou meros "instrumentos") para a realização de determinados fins; mais ainda: tais instrumentos teriam caráter transitório, devendo ser abandonados após a plena realização dos fins almejados.

U ma formulação clara - e, de certo modo, inaugural - dessa perspectiva de interpretação do pensamento político de O liveira Vianna pode ser 
encontrada em dois ensaios de Wanderley Guilherme dos Santos, tratando das relações entre a "ordem burguesa", a "imaginação social brasileira" e a "práxis liberal" no Brasil (SANTOS, 1978). Embora, nesses ensaios, a análise do pensamento social e político brasileiro estenda-se desde as obras dos políticos e publicistas do Império, até autores de meados da década de setenta do século XX, é na caracterização da atmosfera intelectual da década de 1930 que sobressai sua originalidade. Com a justa preocupação em distinguir entre as diferentes modalidades do pensamento autoritário, as quais circulavam naquela década politicamente turbulenta e intelectualmente criativa, Santos observa que, além do autoritarismo justificado com argumentoséticos e naturalistas (como o dos integralistas) e do autoritarismo justificado por razões de ordem histórico-estrutural (Azevedo Amaral e Francisco Campos, por exemplo), havia uma terceira corrente de pensadores autoritários que, diferentemente das duas primeiras, via no "sistema político autoritário" apenas um meio para se chegar a uma "sociedade liberal". Referindo-se às duas primeirasmodalidades de autoritarismo, o autor afirma que

apesar de todas as diferenças, os dois grupos acreditam que o autoritarismo não é uma situação transitória, devido a causas conjunturais. Ao contrário, quanto mais a sociedade progride, mais necessários se farão os regimes autoritários. E nisso, precisamente, reside a diferença entre eles e o grupo que denominei de autoritários instrumentais (SANTOS, 1978, pp. 102 - 103). ${ }^{1}$

Sinais de autoritarismo instrumental seriam visíveis "desde o início da história independente do Brasil". Santos sugere que a "idéia de que cabia ao

\footnotetext{
1 BEIRED (1999) desenvolve uma outra perspectiva para a distinção entre as diferentes modalidades de autoritarismo que vicejavam na década de 30. Argumenta o autor que o traço distintivo do pensamento autoritário representado nas idéias de O liveira Vianna era o "cientificismo" herdado das correntes positivistas de fins do século XIX. Em contraposição, pensadores católicos e integralistas brasileiros, bem como os pensadores de direita na Argentina, organizavam suas idéias segundo um princípio "espiritualista".
} 
Estado fixar as metas pelas quais a sociedade deveria lutar, porque a própria sociedade não seria capaz de fixá-las, tendo em vista a maximização do progresso nacional", é a base tanto do credo, quanto da ação política da elite imperial, inclusive das elites “liberais" (SANTO S, pp.103 - 104)2. Porém, 0 pleno desenvolvimento da "linhagem" do autoritarismo instrumental só se teria processado após a revolução de 1930, como reposta aos desafios econômicos, sociais, políticos e institucionais da década.

Se a difusão do autoritarismo instrumental precisou esperar pelas condições estabelecidas no pós-30, sua formulação intelectual definitiva havia sido apresentada, uma década antes, na obra de estréia de O liveira Vianna. Conforme interpreta Santos,

O liveira Vianna expressou pela primeira vez, tão clara e completamente quanto possível, o dilema do liberalismo no Brasil. Não existe um sistema político liberal, dirá ele, sem uma sociedade liberal. O Brasil, continua, não possui uma sociedade liberal mas, ao contrário, parental, clânica e autoritária. Em conseqüência, um sistema político liberal não apresentará desempenho apropriado, produzindo resultados sempre opostos aos pretendidos pela doutrina. Além do mais, não há um caminho natural pelo qual a sociedade brasi-

2 É bem conhecida a admiração de O liveira Vianna pelas elites políticas do Império. Inúmeras vezes engrandeceu a ação de homens como Feijó, Vaconcelos, Itaboraí, Eusébio, Caxias, Paraná e U ruguai. Segundo José M urilo de Carvalho (1993), O liveira Vianna é descendente desta linhagem. Seriam todosadmiradores do liberalismo, embora conservadores. 0 célebre discurso de Vasconcelosjustificando seu apoio ao Regresso poderia ser tomado como uma prefiguração do autoritarismo instrumental: "Fui liberal. Hoje, porém, é diverso o aspecto da sociedade: os princípios democráticostudo ganharam e muito comprometeram; a sociedade que então corria o risco pelo poder, corre agora o risco pela desorganização e pela anarquia. Como então quis, quero hoje servi-la, quero salvá-la, e por isso sou regressista" (apud M ERCADANTE, 1980, p. 120). Em estudo recente sobre o debate entre o liberal Tavares Bastos e o conservador Paulino José de Souza, o visconde de U ruguai, Gabriela Ferreira contesta a sugestão de Carvalho de que o pensamento de U ruguai seria caracterizado por uma espécie de autoritarismo instrumental, em que o Estado centralizado é apresentado como um educador do povo para o autogoverno e a civilização. Ferreira sugere que, para U ruguai, "a constituição do Estado centralizado parece ser um fim em si mesmo, e adequado à sua visão da sociedade e da nação brasileira" (FERREIRA, 1999, p. 168). 
leira possa progredir do estágio em que se encontra até tornar-se liberal. Assim, concluiria Oliveira Vianna, o Brasil precisa de um sistema político autoritário cujo programa econômico e político seja capaz de demolir as condições que impedem o sistema social de se transformar em liberal. Em outras palavras, seria necessário um sistema político autoritário para que se pudesse construir uma sociedade liberal (SANTOS, 1978, p. 93).

$\mathrm{N}$ ão há dúvidas de que esta interpretação encontra respaldo no que poderíamos caracterizar como a dimensão crítica do pensamento político de O liveira Vianna, ajudando a iluminar aspectos cruciais de suas idéias. 0 intenso esforço de impugnação das pretensões do constitucionalismo liberal, por meio da denúncia da futilidade da tentativa de implantar no Brasil um acervo institucional em desacordo com nosso meio social, é talvez o tema mais recorrente nos escritos políticos do autor. ${ }^{3}$

De fato, desde o primeiro volume de Populações M eridionais do Brasil (1920) até Instituições Políticas Brasileiras (1949), obra máxima de seu pensamento político e constitucional, o autor manteve, com extrema coerência, a tese que constitui seu ponto de partida crítico. No prefácio de Populações..., redigido dois anos antes de sua publicação, esta tese já pode ser observada com todas as letras:

Há um século vivemos politicamente em pleno sonho.(...). O grande movimento democrático da RevoIução Francesa; as agitações parlamentaresinglesas; o espirito liberal das instituições que regem a República Americana, tudo isto exerceu e exerce sobre nossos dirigentes, políticos, estadistas, legisladores, publicistas, uma fascinação magnética, que Ihes daltoniza comple-

3 No capítulo 6 de Administração e Estratégia de Desenvolvimento, Guerreiro RAM O S (1978) chama a atenção para a equívoco de O liveira Vianna, U ruguai e tantos outrosem considerar como um mero formalismo sem resultados práticos a adoção de modelos constitucionais estrangeiros. Acusa esses autores (com os quais simpatiza em muitos aspectos) de não compreenderem os interesses concretos que se abrigavam sob o manto do "formalismo". 
tamente a visão nacional dos nossos problemas. Sob esse fascínio inelutável, perdem a noção objetiva do Brasil real e criam para uso deles um Brasil artificial (1938, pp. XXVIII - XXIX).

Exatamente o mesmo ponto de partida (embora com outra terminologia) encontra-se em Instituições..., quando o autor menciona os três temas que considera os mais importantes de sua obra:

1) Na vida política de nosso povo, há um direito público elaborado pelas elitese que se acha concretizado na Constituição. 2) Este direito público, elaborado pelas elites, está em divergência com o direito público elaborado pelo povo-massa e, no conflito aberto por esta divergência, é o direito do povo-massa que tem prevalecido, praticamente. 3) Toda a dramaticidade de nossa história política está no esforço improfícuo das elites para obrigar o povo-massa a praticar este direito por elas elaborado, mas que o povo-massa desconhece e a que se recusa a obedecer (1974, vol. 1, p. 27).

O s três temas referidos na passagem citada logo acima estão de tal maneira associados, que não é difícil percebermos que se trata, na verdade, de um só tema, o qual foi magistralmente definido na fórmula sintética que expressa a disjunção e a oposição entre o "país legal" e o "país real". ${ }^{4}$

4 Celebrizada na década de 30, a fórmula não era exclusividade de O liveira Vianna, embora tenha sido ele, mais do que qualquer outro pensador, a utilizá-la como instrumento cognitivo para o diagnóstico do Estado brasileiro. Conforme observou Santos, desde as últimas décadas do século XIX, assistia-se a um importante movimento de transformação na "imaginação político-social" brasileira. Por um lado, "a importância do comportamento individual como matéria-prima para a análise política declinará, enquanto questões econômicas e sociais passam a exercer atrativo crescente como substância mesma dosargumentospolíticos". Por outro lado, desenvolve-se um estilo de pensamento baseado em dicotomias, oposições e polarizações, que marcaria profundamente sucessivas gerações de pensadores brasileiros no século XX. Santos atribui a Euclides da Cunha originalmente em seu ensaio Da Independência à República de 1900 - o desenvolvimento do estilo de análise com base em dicotomias. Euclides concebeu a existência de dois Brasis: "um, urbanizado, litorâneo, desenvolvendo-se com benefícios da ação governamental; outro, constituído pelaspopulações rurais, estagnado, ou sobrevivendo por si mesmo, fora do âmbito da ação dos interesses 
Esta fórmula define, da maneira mais resumida possível, o eixo principal da crítica de $O$ liveira Vianna a todas as Constituições liberais experimentadas no País desde o Império.

Contemplando o conjunto de suas críticas à inadequação do modelo constitucional liberal-democrático para o Brasil, é possível destacar três principais debilidades deste modelo, recorrentemente referidas pelo autor. Primeiro: ao estabelecer um princípio federativo que atribuía alta margem de autonomia aos governos estaduais, o modelo liberal inviabilizaria a elaboração e implementação de uma política orgânica voltada para os interesses nacionais, permitindo, ainda, que a política do Executivo central permanecesse submissa aos interesses das mais poderosas oligarquias regionais. O liveira Vianna denunciava

o erro de sempre colocar o problema político acima do problema administrativo - e procurar a solução deste na Federação. Esta, para o Brasil, é a forma menos aconseIhável de descentralização - e isto porque - pela nossa desmedida extensão territorial, pela nossa disseminação e dispersão demográfica, pela peculiaridade da nossa colonização por 'saltos', pela estruturação clânica dos nossospartidos (...), a descentralização política terá que resultar fatalmente em mandonismo, em coronelismo, em regulismo, em satrapismo, em dissociacionismo, em separatismo (1974, vol. 2, p. 148).

Segundo: a organização constitucional inspirada no liberalismo político tenderia a atribuir demasiada importância ao papel das assembléias no processo decisório estatal, um papel caracterizado como incompatível com as transformações econômicas e sociais experimentadas pelas sociedades modernas, cujas administrações exigiam decisões rápidas e complexas. Sur-

governamentais (...). A análise de Euclides da Cunha abre caminho pelo qual vai enveredar número cada vez maior de analistas. As duas décadas seguintes testemunharão a crescente influência de escritores como Alberto Torres, O liveira Vianna e Gilberto Amado, cuja característica teórica distinta é a percepção de contrastes, oposições, polarizações" (SANTOS, 1970, pp. 149 - 151). 
ge daí a proposição de que as funções legislativas, principalmente nos campos econômico e social, se deslocassem dos parlamentos independentes para os conselhos técnicos encastelados no poder Executivo central. A obra legislativa nas nações modernas deveria estar condicionada, cada vez mais, aos imperativos da razão técnica, escapando assim às intermináveis discussões parlamentares, caracterizadas pela indevida intromissão de políticos leigos nos assuntos so bre os quais caberia legislar. O liveira Vianna sublinhava "a incapacidade técnica das elites propriamente político-partidárias para realizarem a obra da administração e do governo", concluind o que, por essa razão, "por toda a parte a competência técnica vai substituindo a competência parlamentar" (1974a, p.119 e p.121).

Terceiro: o modelo democrático liberal permitiria que a irracionalidade e o apoliticismo prevalecentes no comportamento popular pudessem ser transferidos para as esferas decisórias estatais. N este aspecto, o autor desenvolveu suas idéias em sintonia com o pensamento conservador europeu de fins do século XIX e das primeiras décadas do século XX, opondo-se vigorosamente às reformas direcionadas à expansão da cidadania política e sintetizadas na instituição da universalidade do sufrágio. ${ }^{5}$ Segundo O liveira Vianna, a irracionalidade e a incapacidade política do povo brasileiro teriam passado a dominar a esfera pública desde quando, por ocasião da Independência, institui-se o sufrágio universal. A transformação do povo em soberano constitucional seria a principal causa da desorganização nacional e do clima de "tumultos" e "propelias" nas eleições. Por isso, lamentava "a anarquia formidável nascida do, ou com o, universalismo do sufrágio" (1974, vol.1, p. 264), e o fim da "fisionomia grave e pacífica das reuniões eleitorais", atribuindo tal fenômeno ao fato de que passaram a ser eleitores, em pé de igualdade com a antiga "nobreza da terra" - todos os residentes da Colônia,

5 É notável a similitude da argumentação de O liveira Vianna com a de pensadores europeus, tais como Mosca e Pareto, a propósito da "futilidade", da "perversidade" e/ou da "ameaça" da instituição do sufrágio universal. Para a análise dos pensadores europeus, ver: HIRSCH M AN (1995). 
maiores de 21 anos, "mesmo os analfabetos, mesmo os mestiços. Toda a peonagem das cidades. Toda a peonagem dos campos. Toda esta incoerente população de pardos, cafuzos e mamelucos infixos, que vagueavam então pelos domínios" (1974, vol.1, p. 260).

Se avaliada conforme a relevância sociológica de cada uma dessas três debilidades, a ordem de importância e dramaticidade delas é inversa à ordem exposta acima. N osso mais grave problema residiria na estrutura do povo-massa e nos complexos culturais que o dominam, fonte de nosso direito costumeiro, contra a qual se estilhaçariam as frágeis Constituições liberais. Em seguida, surgiria o problema do pernicioso predomínio da "politicalha" - abrigada nas assembléias e movidas pelo "espírito de clã" sobre o Poder Executivo, este potencialmente apto a agir em nome dos interesses nacionais, por meio de seus quadros técnicos. Por fim, teríamos o problema das relações entre o Governo Federal e os estados e municípios, problema que, na fórmula da Constituição de 1891, resolvera-se na descentralização política em favor dos "mandões" locais e em detrimento dos "interesses nacionais".

Deste modo, o núcleo da crítica de Oliveira Vianna ao liberalismo político reside em sua análise sociológica da cultura política do povo brasileiro. 0 "apoliticismo da plebe" seria o fator desconhecido pelos "idealistas utópicos" do constitucionalismo liberal. Faltaria aos nossos propagandistas de modelos constitucionais estrangeiros a consciência "objetiva" da estrutura e do processo de constituição do "povo-massa" no Brasil. Afirmando ter submetido o povo brasileiro a uma "análise objetiva", conclui que este é incapaz de autogoverno. Por quê?

Em face de seus primeiros textos, especialmente de Populações M eridionais do Brasil, o leitor é, muitas vezes, levado a crer que a razão explicativa para a incapacidade política atribuída ao grosso da população brasileira encontra-se nas características de sua composição étnica. As referências a determinados aspectos morais e comportamentais, apresentados como próprios de segmentos raciais específicos, poderiam justificar uma tal inter- 
pretação. Impossível ignorar suas observações sobre os dotes "aristocráticos" da raça ariana, sobre a disposição para a obediência dos "mestiços superiores", ou sobre o comportamento do "mestiço inferior", tipo étnico que seria, "por exigências de sua própria psicossociologia, um excessivo, um instável, um irregular, um descontínuo, um subversivo", para quem "a anarquia é a verdadeira liberdade" (1938, p. 234).

Todavia, a fragilidade desta explicação para o "apoliticismo da plebe" é hoje mais do que evidente. E o próprio autor percebeu isso em sua época, provavelmente motivado pelas críticas de seus contemporâneos. No prefácio à segunda edição de Evolução do Povo no Brasil, de 1933, é bastante claro ao afirmar que "a questão do dólico-louro, da sua superioridade etc. reduziu-se muito da sua importância e acabou saindo do horizonte das minhas preocupações, pelo menos no que concerne ao Brasil" (1933, p. 3). ${ }^{6}$

Reduzida a importância da explicação sociobiológica, a tese da impossibilidade de uma relação adequada entre o povo brasileiro e as instituições liberais passa a sustentar-se primordialmente no fato de que nossas populações, em seu processo de formação histórica, jamais teriam experimentado qualquer coisa semelhante às "comunidades de aldeia" ou "escolas práticas de democracia". 7 Assim, aquele "complexo cultural" que se formou em certos povos europeus (especialmente nos anglo-saxões e, em menor medida, nos germânicos) e que constitui as condições sociológicas da democracia, não encontrou oportunidades de afirmação no Brasil. Nossa história é mais recente, e seu desenrolar teria sido outro. Ao invés das "tradições comiciais", da prática solidária na tomada de decisões públicas, da participação política espontânea, o que O liveira Vianna observa, desde o limiar da colonização, é uma população dispersa nos domínios rurais e inteiramente submissa aos

6 Têm razão os analistas que assinalam que a "explicação" de fundo sociobiológico passa a ocupar um papel marginal no pensamento político de nosso autor, em vista de que os fatores causais de natureza histórica e sociológica tornam-se cada vez mais determinantes em sua argumentação. Por exemplo: DINIZ E LIMA (1971, pp. 88 - 89), M ADEIRA (1991, pp. 8 - 9) e M ORAES (1993, pp. 99 - 101). 7 A única exceção reconhecida por O liveira Vianna é o caso da Vila de Piratininga, estudada como exceção, no capítulo VI de Instituições Políticas Brasileiras. 
senhores desses domínios, uma população ansiosa pela benevolência desses poderosos chefes de clã e inteiramente dependente de sua proteção.

Para o autor, não é de uma total ausência de solidariedade que se deve falar, mas da existência de uma solidariedade circunscrita aos valores e interesses dos clãs parentais e feudais, expressões do despotismo e do personalismo de senhores rurais. 0 fato é que nossa formação social

se processou dentro do mais extremado individualismo familiar. É claro que de tudo isto outra coisa não se poderia esperar senão este traço cultural tão nosso, caracterizado pela despreocupação do interesse coletivo, pela ausência de espírito público, de espírito do bem comum, de solidariedade comunal e coletiva e pela carência de instituições corporativas em prol do interesse do "lugar", da "vila", da "cidade" (O IVEIRA VIAN NA, 1974, vol. 1, p. 118).

A realidade não percebida por todosos "idealistas utópicos" que povoaram a H istória do Brasil independente é que a "solidariedade clânica" fora o verdadeiro fator organizativo de nossos partidos políticos, no momento de criação dos partidos de base nacional por exigência da Constituição de 1824. Simultaneamente à criação dos partidos liberal e conservador, instituiu-se 0 sufrágio universal e, com isso, reuniram-se as condições para a metamorfose do clã feudal em clã eleitoral, já nos primórdios do Brasil independente.

Deste modo, a explicação do "apoliticismo" do povo brasileiro pouco tem de determinismo racial. Se é possível falarmos em determinismo - e creio que seja -, trata-se de um determinismo sociológico, conforme observou Q uartim de M oares, acentuand o que "a problemática da democracia em O liveira Vianna é formalmente impecável. Consiste em determinar as condições sociológicas do autogoverno" (M O RAES, 1993, p. 89).

\section{Autoritarismo Instrumental ou Estatismo Autoritário?}

Com isso, podemos retornar às formulações dos intérpretes de Oliveira Vianna, que operam com a noção de "autoritarismo instrumental". 
Até este ponto de nossa análise, parece ser possível concluir pela utilidade das proposições desse modelo de interpretação para lançar luz sobre um dos aspectos centrais do pensamento político de nosso autor. 0 modelo ilumina consideravelmente o esforço crítico que o sociólogo fluminense empreendeu para demonstração das debilidades do constitucionalismo liberal em contextos marcados pela ausência de seu suposto substrato sociológico, só plenamente encontrado nos povos anglo-saxônicos.

Mas o modelo do autoritarismo instrumental pretende ir mais adiante, pois, além de iluminar a dimensão crítica e sociológica do pensamento de O liveira Vianna, contém proposições em torno do que poderíamos qualificar como a dimensão ideológica de suas idéias políticas, sem deixar claro em que ponto termina uma coisa e começa outra. É aí que o referido modelo de interpretação começa a revelar seus limites. Embora a força e 0 sentido dos argumentos de O liveira Vianna sejam resultantes das determinações recíprocas entre essas duas dimensões de seu pensamento político, parece-nosnecessário operar uma distinção analítica entre ambas. ${ }^{8}$ É precisamente a ausência de tal distinção que está na base das limitações da noção de autoritarismo instrumental, quando utilizada para a compreensão do pensamento político de O liveira Vianna. Supõe-se uma duvidosa homologia entre os enunciados analíticos e os enunciados normativos presentes no discurso do autor, o que resulta em conclusões altamente questionáveis sobre a ideologia política subjacente ao seu programa de reformas institucionais.

Como deve estar claro, ao nos referirmos à dimensão ideológica das idéias de O liveira Vianna, não pretendemos sugerir que suas concepções careçam de capacidade científica para revelar problemas concretos da socie-

8 Certamente não se trata aqui de pensar nos termos de uma oposição entre tais dimensões. Tradicionalmente, o conceito de ideologia tem sido compreendido numa problemática de caráter epistemológico, em que se dá destaque para questões como as oposições entre ciência e ideologia, entre a verdade e a falsidade das idéias, utilizando-se categorias como as de inversão, obscurecimento e falsificação para a definição dosfenômenos ideológicos. De maneira alternativa, entendemos ideologia - seguindo as sugestões de THOM PSO N (1984 e 1995) - como sistemas de "formas simbólicas" que atuam na legitimação de determinadas estruturas de dominação. Ideologia não é 
dade e do Estado no Brasil. 0 destaque à dimensão ideológica de seu pensamento em nada diminui a relevância de suas contribuições de sociólogo e historiador. Ao contrário, a análise da dimensão ideológica de seu pensamento pode ser de extrema valia para compreendermos as opções de objeto e método de sua Sociologia política.

A nosso ver, a dimensão ideológica do pensamento político de O liveira Vianna explicita-se de modo enfático em suas reflexões sobre o Estado, mais especificamente, em suas concepções sobre a forma de Estado "adequada"9 à realidade brasileira. A riqueza e a densidade de seus ensaios sobre o diagnóstico das deficiências de nossas instituições políticas não são mais notáveis do que sua insistência na proposição de rumos para um processo de reforma institucional, destinado a corrigir tais deficiências.

É com este espírito pragmático que o autor assinala "a íntima conexão entre as ciências do Estado e as ciências da sociedade e indispensabilidade

necessariamente mistificação, encobrimento ou inversão da realidade, embora as ideologias possam assumir essas formas. A especificidade dosfenômenos ideológicos não deve ser determinada tendo-se em vista seus aspectos contingentes de oposição à "verdade" ou à "realidade", mas sim considerando-se a natureza funcional das formas simbólicas. Ideologia é sentido em função da dominação. Conforme Thompson: "A análise da ideologia está primeiramente interessada nas maneiras como as formas simbólicas se entrecruzam com relações de poder. Ela está interessada nas maneiras como o sentido é mobilizado, no mundo social, e serve, por isso, para reforçar pessoase grupos que ocupam posições de poder" (THO M PSO N, 1995, p. 76). A ideologia não é uma mera ilusão desconectada da vida material, pois se trata da manifestação simbólica do fenômeno da dominação, o qual só opera materializado em práticas e instituições. Assim definido, o conceito de ideologia inscreve-se numa problemática que é muito mais de natureza sociológica do que epistemológica, pois, "uma ideologia não é necessariamente 'falsa': quanto ao seu conteúdo positivo, ela pode ser 'verdadeira', muito precisa, pois o que realmente importa não é o conteúdo afirmado como tal, mas o modo como este conteúdo se relaciona com a postura subjetiva envolvida em seu próprio processo de enunciação. Estamos dentro do espaço ideológico propriamente dito no momento em que esse conteúdo - 'verdadeiro' ou 'falso' (se verdadeiro, tanto melhor para o efeito ideológico) - é funcional com respeito a alguma relação de dominação" (ZIZEK, 1996, p. 13).

9 A idéia de "adequação" é uma constante no pensamento político de O liveira Vianna. A adequação, como princípio de fundamentação do governo autoritário, tem raízes profundas no pensamento político ocidental. H annah Arendt chama a atenção para a sua centralidade na teoria platônica da autoridade política. A idéia de "adequação" corresponde à idéia de bem (bondade), a que Platão recorrera, em substituição à idéia de "beleza", para ocupar a função de forma reguladora da qual dependeriam todas as demais idéias. Inicialmente, em $O$ Banquete e no Fedro, obras em que 
destas para a solução dos problemas daquelas" (1974, v. 2, p. 49), para, logo em seguida, referindo-se à influência que recebera das idéias de Alberto Torres, afirmar que, tal como o mestre,

não queria o estudo da sociologia no sentido da ciência pura, de investigação desinteressada das leis da vida social - da investigação pela investigação; mas, sim, como uma base de orientação pragmática, como um processo de coleta de dados concretos, sobre os quais se deveria apoiar a solução objetiva e realística dos nossos problemas nacionais" (1974, v. 2, p. 70).

As propostas de reformas institucionais amiúde apresentadas em seus escritos são consideradas pelo próprio autor como derivação de uma análise sociológica "objetiva" e rigorosamente imparcial da sociedade brasileira. Esta sua crença "anti-weberiana" 10 em uma ciência social capaz de assegurar êxito nas opções entre alternativas práticas pode ser interpretada como uma herança da Epistemologia naturalista e positivista, emergente no Brasil desde as últimas décadas do século XIX.

predomina a idéia de beleza, o problema de Platão era revelar a verdade, independente da utilidade e eficácia prática dessa revelação. "A função original das idéias não era governar ou determinar de alguma outra maneira o caos dos assuntos humanos, mas sim, com 'irradiante brilho', iluminar sua escuridão". Em A República (a partir do sexto livro), a idéia de beleza é substituída pela de bem, pois o problema que passa a ocupar Platão já não é mais o da busca da verdade, mas o de como tornar essa "verdade" um padrão de medida do comportamento humano, como torná-la "útil". "Tal utilidade somente poderia ser salva mediante a idéia do bem, já que 'bem', no vocabulário grego, sempre significou 'bom para' ou 'adequado'. Se a idéia máxima da qual todas as demais devem participar para que cheguem a ser idéias é a de adequação, então as idéias são aplicáveis por definição, e, nas mãos do filósofo, o que é versado em idéias, podem tornar-se regras e padrõesou, como posteriormente em Leis, se converter em leis" (ARENDT, 1988, pp. 152 - 154). Com efeito, em O Idealismo da Constituição, O liveira Vianna afirma algo muito a propósito da solução de Platão para a fundamentação do governo autoritário: "O que devemos querer não são regimes belos ou harmônicos, mas regimes convenientes e adaptados ao nosso povo" (1939, p. 116).

10 É bem conhecida a posição de Weber sobre o que considerava o "absurdo" da tentativa de justificação científica de determinadas posições práticas. Conforme afirma enfaticamente em um de seus mais conhecidos ensaios metodológicos, "jamais pode ser tarefa de uma ciência empírica proporcionar normas ou ideais obrigatórios, dos quais se possa derivar 'receitas' para a prática" (WEBER, 1992, p. 109). 
Em vista disso, não é exagero afirmar que a empreitada sociológica de O liveira Vianna realiza-se sob o primado da ação, uma ação voltada para a resolução prática dos problemas de organização política do País, especialmente para consecução daquilo que o autor considerava a finalidade principal de seus estudos: "uma concepção do Estado brasileiro, enquadrado dentro do Brasil" (1974, vol. 2, p. 74). E qual seria a forma de Estado "adequada" à sociedade brasileira?

A resposta para esta questão, o autor nos oferece sem ambigüidades: o Estado autoritário. 0 modelo do autoritarismo instrumental reconhece e destaca o fato iniludível de que o sistema político que emerge do programa de reformas de $\mathrm{O}$ liveira Vianna é de caráter autoritário. No entanto, conforme já observamos, o modelo sugere que as instituições do Estado autoritário não constituem um fim em si mesmas. Seriam apenas meios - meios realistas, por suposto - destinados à criação uma sociedade liberal, após o que - e não antes ou ao mesmo tempo - o liberalismo político seria viável.

É preciso ressaltar que o caráter instrumental que porventura se queira atribuir às instituições do Estado autoritário depende, em grande medida, do que se compreende por "sociedade liberal". Apenas a título de ilustração, saliente-se que não haveria contradição entre Estado autoritário (enquanto meio) e sociedade liberal (enquanto fim) se esta última fosse claramente identificada à sociedade de mercado. A "sociedade liberal", neste caso, teria uma definição muito particular e que, de modo algum, satisfaz ao amplo conjunto da tradição de pensamento liberal. Trata-se de uma concepção de sociedade liberal típica do liberalismo econômico, que dá preeminência à liberdade de movimentos dos agentes econômicos nos mercados. A autonomia dos indivíduos-cidadãos diante da autoridade estatal e a definição dos direitos de participação na conformação do poder, leitmoviv do liberalismo político, são preocupações secundárias e subordinadas ao mercado nos ideólogos do liberalismo econômico. Hayek, por exemplo, afirma com relação à democracia, que esta seria apenas "um meio, um instrumento utilitário para salvaguardar a paz interna e a liberdade individual". Para, logo em seguida, acrescentar: "Tampouco devemos es- 
quecer que muitas vezes houve mais liberdade cultural e espiritual sob os regimes autocráticos do que em certas democracias" (HAYEK, 1990, p. 84).

Mas não é o liberalismo econômico o telossubentendido no modelo do autoritarismo instrumental. 0 que se supõe ser a meta do Estado autoritário, na ideologia política de O liveira Vianna, é exatamente a liberdade política, que culminaria no autogoverno dos cidadãos pelo exercício consciente e autônomo das liberdades políticas, inclusive da liberdade positiva do sufrágio. Supõe-se que o problema da efetivação da democracia resume-se a uma questão de controle de tempo e de etapas de um processo intencionalmente desencadeado pelas elites estatais. $\mathrm{Não}$ é por acaso que inextrincavelmente associada à idéia de instrumento está a idéia de transitoriedade, para a caracterização do papel da institucionalidade autoritária. Assim, uma das características centrais do autoritarismo instrumental residiria na crença de que

o exercício autoritário do poder é a maneira mais rápida de se edificar uma sociedade liberal, apóso que o caráter autoritário do Estado pode ser questionado e abolido. A percepção do autoritarismo, como um formato político transitório, estabelece a linha divisória entre o autoritarismo instrumental e as outras propostas políticas não democráticas"(SANTOS, 1978, p. 103).

Esta tese é também corroborada por Antônio Paim, quando afirma que, em Oliveira Vianna,

"o autoritarismo é um instrumento transitório a que cumpre recorrer a fim de instituir no país uma sociedade diferenciada, capaz de dar suporte a instituições liberais autênticas" (PAIM , 1987, p. 176). ${ }^{11}$

11 É certo que o recurso à concentração extraordinária de poderes no Executivo estatal, por um determinado período de tempo e para a realização de determinada meta, tem antecedentes na História política ocidental. A Lei Curiata da república romana, que instituiu a figura jurídica da "ditadura comissária", permitia a nomeação de um ditador que, governando acima das leis vigentes, deveria afastar ameaças efetivas à segurança e liberdade na república. Todavia, os romanos levavam a sério o instituto da transitoriedade do regime de exceção, o que explica a fixação, na 
Aqui seria útil outra distinção, desta vez entre o aspecto "instrumental" e o aspecto "transitório" do autoritarismo, que aparecem indevidamente identificados nas definições acima. 0 formato político autoritário pode aparecer como "instrumental" em termosfuncionais, sem implicar necessariamente em "transitoriedade", contabilizada em termos de tempo histórico. Se, por exemplo, admitíssemos a equação "sociedade liberal = sociedade mercantil" não haveria razão para esperar transitoriedade do exercício autoritário do poder. Isto porque a sociedade mercantil não é necessariamente incompatível com o Estado autoritário. Antes pelo contrário, em determinadas situações sociais, esta forma de Estado pode ser a mais ad equada para que aquela forma de sociedade se reproduza após já constituída. 0 caráter instrumental do autoritarismo nada tem a ver com "transitoriedade", pois a permanência do autoritarismo pode ser o "meio" político mais eficaz para a reprodução de determinada ordem social. Na perspectiva da ordem liberalmercantil, a forma específica do Estado e do sistema político é uma questão em aberto. Não há por que imaginar um telos democrático imanente a tal perspectiva, que aceitaria apenas provisoriamente 0 autoritarismo como um instrumento para a constituição de uma nova institucionalidade, fundada na liberdade política e na soberania popular.

Entretanto, vale novamente observar, o que está suposto como o fim do Estado autoritário no pensamento de O liveira Vianna, segundo a tese do autoritarismo instrumental, é a afirmação dos direitos de participação política da população. Resta a dúvida se é possível compreender expressões como "sociedade liberal", "liberalismo político" ou "instituições liberais autênticas", mobilizadas nos textos de Santos e Paim, como expressões comutáveis com o termo "democracia". A bem da verdade, tal comutabilidade está apenas implícita nesses autores.

Constituição, de um período bem determinado para a vigência da ditadura. "O ditador era nomeado apenas para a duração do dever que Ihe fora confiado e, de todo modo, por um período não maior do que seis meses e não maior do que a permanência em cargo do cônsul que o havia nomeado" (BO BBIO , 1987, p. 159). 


\section{Fins Democráticos por M eios Autoritários?}

Todavia, há variações mais radicais do modelo do autoritarismo instrumental, explicitando o que está apenas subentendido nas elaborações acima mencionadas. Q uartim de M oraes, por exemplo, após afirmar com razão a nosso ver, que "o núcleo semântico mínimo da noção de autoritarismo consiste na relação de exclusão recíproca que a opõe à noção de democracia" (M O RAES, 1986 , p. 205), reafirma a tese do autoritarismo instrumental, porém sugerindo que o autoritarismo de 0 liveira Vianna não é apenas politicamente liberal, mas, antes, filosoficamente democrático: "O autoritarismo de O liveira Vianna é concebido filosoficamente como um pis-aller: não representa um valor absoluto (...), masum meio político para uma terapêutica social. O horizonte ideológico para o qual aponta esta terapêutica é democrático" (p. 215).

Seria possível, sem dúvida, relacionar passagens em que O liveira Vianna procura sugerir sua admiração ao modelo de organização política anglosaxônico e insinuar sua profissão de fé liberal-democrática. Num capítulo de 0 Idealismo da Constituição, inteiramente dedicado ao exame do "segredo da opinião inglesa", o autor afirma sem rebusco: "uma coisa sempre me maravilhou: o poder da opinião inglesa" (O LIVEIRA VIAN NA, 1939, p. 221). Já no prefácio à segunda edição de Problemas de Política O bjetiva, datado de dezembro de 1945, a sugestão assume forma ainda mais direta: "Concordo que me qualifiquei de antifederalista e de antiparlamentarista - e aceito com honra e mesmo orgulho o qualificativo. Não, porém, de antiliberal, nem de antidemocrático. Não sou uma coisa nem outra. Sou justamente $o$ oposto disto" (1974a, p. 22).

Porém, são passagens tão isoladas e circunstanciais, que dificilmente poderiam servir para sustentar a existência de algo como uma teleologia democrática orientando o pensamento político do autor. Ademais, na primeira passagem citada no parágrafo acima não está dito que haja admiração pela democracia, massim pela "opinião" inglesa. A democracia funciona porque a 
opinião pública é "organizada". Pode-se concordar que democracia e opinião pública sejam conceitos associados, mas de modo algum idênticos.

Com relação à segunda passagem, a data em que foi escrita não é fator de menor importância para sua interpretação. Em dezembro de 1945, pouco mais de um mês após a queda da ditadura Vargas, momento de revitalização das forças liberais, desassociar-se dos escombros das instituições estadonovistas talvez fosse uma questão de sobrevivência intelectual. Não vai aqui, evidentemente, nenhuma sugestão de que estamos diante de um embuste deliberado, mas sim que, mesmo em um autor com a lucidez de $O$ liveira Vianna, procedimentos discursivos motivados por autodefesa e expressos em racionalizações podem fazer-se presentes. 0 pinião semelhante encontra-se em estudo recente sobre o pensamento político de O liveira Vianna, que também contesta "a intuição de que o autoritarismo seria instrumental para a obtenção do liberalismo e da democracia", uma vez que o recurso a tais conceitos

são sempre concessões retóricas de Vianna, feitas ou para adocicar o argumento ou em momentos em que elasse tornavam necessárias, como em 1945 (...). Além disso, os conteúdos de democracia e liberdade em Vianna são muito distintos dos conteúdos clássicos que nos autorizariam a concluir pelo seu liberalismo e pelo seu espírito democrático (PIVA, 2000, p. 95).

Com efeito, a idéia de democracia é mobilizada de modo sistemático nos textos de O liveira Vianna, embora raramente como valor positivo quando associada à idéia de liberalismo político. De um modo geral, a democracia aparece, em associação com o liberalismo, com uma conotação negativa, como nas inúmeras passagens em que o autor se ocupa em demonstrar a inadequação desta associação à realidade social brasileira, tal como observamos anteriormente. Todavia, o termo democracia assume também uma dimensão positiva, representando um verdadeiro ideal de organização 
política da nação. 0 ponto importante - e decisivo - a se destacar é que O liveira Vianna realiza uma operação de desassociação entre democracia e liberalismo político, quando realiza o elogio da democracia "adequada" à sociedade brasileira. M as que tipo de democracia O liveira Vianna idealiza como alternativa à democracia liberal?

A resposta só pode ser esta: a "democracia corporativa", também traduzida em expressões como "democracia profissional", "verdadeira democracia" e "democracia autoritária". Q uanto ao conteúdo deste tipo de democracia, é possível afirmar, com ampla corroboração dos textos do autor, que ela nada tem em comum com o conteúdo presente nas diferentes elaborações do modelo democrático liberal. Mesmo que nos fixássemos numa definição minimalista e conservadora das características da democracia liberal, seria difícil não constatar sua maior permeabilidade à participação popular, comparada ao que O liveira Vianna qualifica como a "verdadeira democracia". N a variante da democracia liberal caracterizada pelo "elitismo competitivo", à maneira de Schumpeter (1984), ao menos fica resguardado o direito de sufrágio às grandes massas da população. Em O liveira Vianna, ao contrário, a democracia "pode perfeitamente realizar-se sem eleições e mesmo sem eleitores" (O LIVEIRA VIAN NA, 1927, p. 90).

Por outro lado, a rejeição da representação definida pelo voto não se realiza em favor da participação direta da população nos negócios públicos, a exemplo de Rousseau. Nada mais distante do ideal "democrático" de O liveira Vianna. Sobre este ponto, ele foi suficientemente explícito: "Não tenho nenhuma confiança nos processos da democracia direta em nosso país; não aceito, pois, nem a iniciativa nem o referendo" (1974 a, p. 191). Assim, a "verdadeira democracia" é tão refratária à tradição da democracia participativa, quanto à tradição da democracia representativa.

$\mathrm{N}$ a democracia de opinião pública organizada, almejada por O liveira Vianna, o que deve estar bem representado é o interesse particular das diversas corporações profissionais. O rganizar a opinião corresponde ao for- 
talecimento de sindicatos e associações profissionais representativos dos diversos setores de algum relevo na esfera econômica. Não se imagine, porém, que tal fortalecimento se reverta em autonomia das corporações diante do Estado, pois o próprio reconhecimento da existência das corporações ocorre no âmbito do Poder Executivo estatal. Além disso, no que diz respeito ao processo decisório estatal, o poder de cada corporação particular não ultrapassa a capacidade de comunicar aos governantes de fato - as elites do Poder Executivo - seus anseios e necessidades, os quais são processados como informações técnicas pelos governantes, com o fim de obter maior realismo, objetividade e eficácia na produção e implementação das políticas públicas. Conforme palavras do próprio autor:

Do que se trata é precisamente de armar o Estado, ou melhor, os responsáveis pela direção política e administrativa da Nação de elementos seguros de informação técnica e experimental sobre as necessidades do povo e as realidades dos nossos grandes interesses coletivos: é o que Laski chamaria 'a organização da informação'. Para isso o que cumpre fazer é pedir aos grupos organizados - tanto profissionais como culturais - a sua colaboração, chamando-os para junto do Estado, dandoIhesum lugar preeminente nas suas atividades, nosseus tribunais, nos seus conselhos, nos seus parlamentos justamente o lugar preeminente que, por um equívoco secular, temos até agora dado aos partidos. Só assim poderemosorganizar, aqui, aquela 'democratie technique et ordonneé', a que se refere Henri Janne e que é a única forma eficiente de democracia, não só no mundo de hoje, como no mundo de amanhã (1939, pp. 220 221- grifos no original).

Desse modo, a representação corporativa pode ser compreendida como um meio de coleta de informações para subsidiar o processo "técnico" da produção legislativa, processo que o autor propõe que se retire das 
prerrogativas das câmaras, para ser totalmente encampado pelas agências de um Poder Executivo hipertrofiado. Conforme observou Evaldo Vieira,

as corporações, como são concebidas por O liveira Vianna, (...) legitimam o uso da força estatal principalmente nas questões econômicas, além de transformarem o Estado no grande realizador da 'paz social'. Desta maneira as corporações e seu Direito Corporativo nada mais são que fatores de legitimação da ação estatal, que articula a nação de cima para baixo, segundo a força de sua autoridade (VIEIRA, 1981, p. 133).

Em face disso, duas questões se impõem: 1) Em que agências estatais realizar-se-ia a "política objetiva", informada pela síntese dos conhecimentos especializados dos representantes das diversas corporações? 2) Dado que cada representante de corporação tem necessariamente uma visão fragmentada do processo social, já que moldada na sua experiência particular no âmbito profissional, quem estaria em condições de realizar a referida síntese? A resposta a tais questões define o núcleo do modelo político idealizado por O liveira Vianna para o Brasil, ao mesmo tempo em que nos afasta da interpretação deste ideal com base no modelo do autoritarismo instrumental.

\section{Conselhos Técnicos: o Cérebro do Estado}

Em resposta à primeira indagação, é possível afirmar que o núcleo legislativo e decisório estratégico, na arquitetura institucional do sistema político idealizado por O liveira Vianna, surge cristalizado na instituição dos "conselhos técnicos" (SILVA, 2001). É no âmbito de tais conselhos que ganha sentido a proposição de uma "política objetiva", uma espécie de ação estatal que teria uma dupla superioridade à política tradicional: por um lado, por ser concebida sem a interferência do "espírito de clã" e do "facciosismo" dos políticos tradicionais, abrigados nas Câmaras e nos Partidos; 
por outro, por ser sensível à opinião técnica e científica, incorporando especialmente o conhecimento sociológico em sua própria elaboração. O sconselhos funcionariam como uma espécie de "cérebro do Estado", 12 atuando em íntima associação com o Poder Executivo. Porém, mais do que um instrumento do pensamento e da ação do Presidente da República, tais instituições são idealizadas como um quarto poder, com prerrogativas de intervenção, julgamento e veto sobre os demais poderes da República.

O sconselhos técnicos surgem, no discurso de O liveira Vianna, como uma imposição dos fatos por ele descritos e não meramente como um ideal político. 0 argumento era de que as transformações operadas nas sociedades contemporâneas, sobretudo as de natureza econômica, impunham, aos executores da política estatal, a necessidade de decisões mais ágeise tecnicamente mais bem informadas. 0 princípio da separação e independência dos poderes teria o inconveniente de retardar o processo decisório, além de permitir que políticos facciosos e leigos em assuntos técnicos, abrigados nos Partidos Políticos e nas Câmaras, criassem obstáculosà ação desimpedida dos governantes de fato, as elites do Poder Executivo.

Para provar esta tese, 0 autor procura demonstrar, mediante a análise da experiência de diferentes países, que "por toda a parte a competência técnica vai substituindo a competência parlamentar" (1974a, p.121). Inicia essa demonstração analisando as mudanças no modo de governar na Inglaterra, berço e epicentro da democracia liberal. Mesmo na "Inglaterra dos parlamentos onipotentes (...) o centro de gravidade da vida política não é mais o Parlamento" (p.122). A criação do "Secretariado de Gabinete", nos anos da primeira guerra, teria representado uma inovação institucional definitiva. Este Secretariado, composto por "técnicos escolhidos" diretamente pelo Primeiro-M inistro, formava um "organismo novo", uma "organização

12 Expressão alusiva à caracterização que Joaquim Nabuco fez do Conselho de Estado, o "cérebro da monarquia", durante o segundo Império. Para uma análise detida dessa instituição, confirmando a caracterização de Nabuco, ver: CARVALHO (1996). 
de serviços especializados", resultando num "sistema objetivo e prático de informação técnica" (p.123).

A criação do Secretariado de Gabinete viria a reforçar uma tradição legislativa de natureza técnica, própria dos ingleses, que se manifesta no "processo de pesquisas, investigações, vistorias, isto é, inquéritos (inquiries), realizados nos próprios meios profissionais interessados". Processo semeIhante de elaboração legislativa ocorria na Bélgica, principalmente nas "chamadas leis econômicas e sociais", para as quais se tem "o cuidado de fazer longas e minuciosas sondagens" (1974a, p.124). O liveira Vianna mostra que em outros países, como na Itália, na Alemanha e na França, a situação era semelhante, embora nesses países não houvesse a tradição inglesa dos "inquéritos". o mecanismo pelo qual se garantiria a natureza técnica da obra legislativa seria outro, porém regulado pelo mesmo princípio: “a colaboração das classes na obra legislativa". Ao invés de as classes serem ouvidas por meio dos "inquéritos", seriam ouvidas "por meio do mecanismo dos Conselhos Econômicos" (1974a, p. 125). Cita o exemplo do Conselho Nacional Econômico, criado na França em 1925, "um Conselho de Técnicos", e do Conselho Superior de Economia Nacional da Itália. O autor refere-se entusiasticamente a este último, criado em 1923, funcionando junto ao M inistério da Economia Nacional e compondo-se de 45 membros, todos técnicos, pertencentes a várias especialidades. "Todas as deliberações do Conselho são comunicadas ao Ministério da Economia ou às autoridades competentes para sua devida execução". A legitimidade deste Conselho estaria demonstrada, segundo ele, pelo fato de que

os italianos da Terceira Itália dispensam (...), na sua legislação econômica e social, a homologação do Parlamento. O sprojetos de lei saem diretamente deste Conselho técnico para osórgãos executivos do governo, sem passarem, nem mesmo em visita de cortesia, pela grande assembléia tradicional (1974a, p. 125). 
A composição dos conselhos técnicos deveria levar em consideração a participação dos "práticos", dos "entendidos" em determinados temas. Só estes poderiam trazer a vivência dos problemas reais da organização da produção. Por isso, os membros das associações de classe seriam presenças indispensáveis nos Conselhos, ao lado dos técnicos e administradores do Poder Executivo.

Após a análise da evolução dos métodos de governo em diferentes países, em que se configura a crescente importância dos conselhos técnicos, O liveira Vianna lamenta a pouca importância atribuída a tais instituições no Brasil. Embora já existissem àquela época conselhos nacionais em funcionamento, como o Conselho Nacional do Trabalho e o Conselho Superior da Indústria e do Comércio, ambos criados em 1923, o autor chama a atenção para a necessidade de remover "certos preconceitos muito radicados na mentalidade de nossas elites", que reduzem a eficiência destas "grandes corporações técnicas". E o principal destes preconceitos, "o mais grave, o mais absurdo, o mais anacrônico é a crença na competência onisciente dos parlamentos" (1974a, p. 141).

Todos os argumentos do autor a propósito da centralidade e da importância crescente dos conselhos técnicos confluem para a proposição de um amplo e poderoso Conselho Nacional para o Brasil. Tal proposição fazia parte de seu projeto de revisão da Constituição de 1891, sendo que algo semelhante fora incorporado à Constituição do Estado $\mathrm{N}$ ovo $^{13}$. Este organismo deveria ser "composto de 15 a 21 membros, escolhidos entre as personalidades mais eminentes do país, que se hajam feito notáveis nos vários

13 Na letra da Constituição de 1937, encontra-se a instituição do Conselho da Economia N acional, nunca realmente posto em funcionamento sob o Estado N ovo. Em sua apologia desta Carta constitucional, levada a cabo na segunda edição de $O$ Idealismo da Constituição, O liveira Vianna insiste na importância da atribuição de funções legislativas, além das funções consultivas já estabelecidas, para o devido fortalecimento do Conselho Nacional, o qual, "não sendo propriamente um poder poderá vir a sê-lo, se Ihe for atribuída a competência legislativa, a que se refere o artigo 63 da Constituição" (1939, p. 128). 
domínios do conhecimento, especialmente nas ciências morais e políticas" (1974a, p. 183). Q uanto às atribuições e faculdades de tal Conselho, 0 autor destaca as seguintes:

a) Resolver sobre a intervenção do governo federal nos Estados, o prazo e a extensão dos poderes desta intervenção.

b) Direito de veto a certos atos emanados dos outros poderes políticos.

c) Competência para resolver os conflitos entre os diversos poderes da União e dos estados.

d) O pinar sobre projetos de lei, de partidos ou da Câmara Federal ou do Poder Executivo.

e) Julgar os membros do Supremo Tribunal Federal e os demais membros da magistratura.

f) Controle, com direito de veto, sobre as propostas da Câmara Federal relativas à fixação dos subsídios dos deputados federais e do presidente da República.

g) Competência para determinar o número de deputados que devem compor a Câmara Federal e o critério da sua distribuição por Estados.

Em suma, os conselhos técnicos são concebidos como espaços-chave no processo decisório da política do Executivo Estatal, com poderes de intervenção, veto e julgamento sobre as ações de todos os poderes da República. Mais do que isso, sua institucionalização é considerada "o verdadeiro caminho da democracia no Brasil" (1974a, p. 147). Q uanto ao pressuposto sociológico para a efetivação dos conselhos técnicos, manifesto na difusão da solidariedade profissional, o autor não dá garantias de que isso possa um dia realizar-se, mas enfatiza que

se esta solidariedade puder um dia ser conseguida, podemos esperar tranqüiloso advento da Democracia no Brasil. Porque a pedra de toque do governo do povo pelo povo em nosso país está nisso: na capacidade das 
nossas classes produtoras de organizarem-se profissionalmente. Sem isto, o melhor é contentarmo-nos com o que está: com o governo do povo por oligarquias broncas, que todos os espíritos capazes de idealidade deverão pugnar para que se transformem em oligarquias esclarecidas (1939, p. 248).

\section{Tecnocracia, a Elite Especial}

Para concluir, resta-nos responder brevemente a questão relacionada a quem, no âmbito dos conselhos técnicos, estaria em posição de realizar a síntese dinâmica das informações e demandas provenientes das organizações sindicais e corporativas. Como sugere acertadamente um dos propositores da noção de autoritarismo instrumental para a compreensão do pensamento de O liveira Vianna, tais agentes encontrar-se-iam entre "as elites sociologicamente iluminadas" (M O RAES, 1993, p. 125). O u, em outras palavras do mesmo autor, entre as "elites meritocrático-tecnocráticas" destinadas à realização de um "programa intelectual de reforma científica da sociedade brasileira" (p. 123).

É certo que o termo "tecnocracia" não freqüenta os textos de O liveira Vianna, porém, quem estaria em melhor condição de idealizar as reformas institucionais orientadas cientificamente? E quem teria maior interesse e capacidade de firmar a autoridade da ciência e da técnica na elaboração e na execução das políticas públicas? Talvez a tecnocracia, como prefiguração, ajude-nos a oferecer uma resposta para aquilo que Santos considera uma debilidade do "autoritarismo instrumental" de O liveira Vianna, que "nunca compreendeu totalmente onde deveria procurar os atores políticos aptos a transformar a sociedade brasileira numa comunidade liberal". Não seria a tecnocracia aquela "elite política especial, vinda não se sabe de onde" para a qual "seu pensamento estava sempre voltado" (SANTOS, 1978, p. 106)? 
O liveira Vianna, aferrado à "preeminência do princípio da autoridade sobre o princípio da liberdade" (1952, p. 129), desenvolveu impressionante esforço para justificar a autoridade da ciência social na direção da vida estatal. Como muitos intelectuais de sua época, acreditava na Sociologia como "a arte de salvar rapidamente o Brasil", na célebre expressão de M ário de Andrade. Sob a luz salvadora da Sociologia, deveriam realizar-se as reformas institucionais de que tanto o País precisava. Conforme observou Lamounier, para intelectuais como O liveira Vianna, a proposição de modelosinstitucionais não implica em "exercício de imaginação política, mas de aplicação de capacidade técnico-científica. A tarefa científica da so ciologia é produzir o diagnóstico que conduzirá à sócio-terapia tecnocrática" (1985, p. 365).

Em O liveira Vianna, esse tipo de "objetivismo tecnocrático" está na base de seu realismo ou, como preferia o autor, de seu "idealismo orgânico", um idealismo calcado na observação, na experiência, capaz de antever o desenvolvimento futuro da sociedade, porque baseado nos ensinamentos das "leis sociológicas". As elites estatais deveriam reconhecer que "o poder que tem de modificar ou suprimir qualquer elemento da ordem social" só poderá ser exercido "eficientemente dentro de certas condições - obedecendo às leis da ciência social; do contrário o fracasso é certo" (O LIVEIRA VIANNA, 1974, vol. 2 - grifo no original).

Enfim, parece-nos bastante difícil sustentar a conclusão de que a democracia liberal consista no verdadeiro valor último para o qual tende o pensamento político de O liveira Vianna. Aceitar essa flagrante contradição em termos, que é a noção de "democracia autoritária", substancializada de modo quase exemplar na Constituição de 1937, provavelmente não nos levaria além das inúmeras limitações reinantes nos modelos da democracia liberal. Muito pelo contrário, implicaria um retrocesso tanto no plano cognitivo, quanto no plano político, e a "era da democracia confusa", para usar uma expressão de Sartori (1994), conheceria então seu apogeu. É valiosa a lição da teoria democrática contemporânea de que a democracia procedimental não conduz, por si só, à realização de uma democracia substantiva. Contudo, também parece claro que, sem a existência de uma 
institucionalidade que assegure um mínimo de procedimentos democráticos, o que resta é o Estado autoritário, na melhor das hipóteses paternalista, na pior, tirânico.

\title{
Liberalism and Democracy in O liveira Vianna's Polical Sociology
}

\begin{abstract}
This article examines the political thought of O liveira Vianna by means of a critical dialogue with the model of interpretation that defines as "instrumental authoritarianism" the singularity of his conception of State. In such model of interpretation, the institutions of the authoritarian State idealized and proposed by that author are presented as instruments (means) adjusted for the accomplishment of the political liberalism and the democracy in Brazil. After the liberal and democratic ends were accomplished, the authoritarian character of the State could be questioned and abolished. This article argues that, besides not questioning the equivocal assumption that it would be possible to accomplish democratic ends by means of authoritarian instruments, the "instrumental authoritarianism" model is not appropriate to understanding the ideological dimension of O liveira Vianna's political thought, which is oriented to the justification of an antiliberal and antidemocratic State form.
\end{abstract}

Keywords: Oliveira Vianna. Democracy. Liberalism. Authoritarianism. Brazilian Political Thought.

\section{Referências}

AREN DT, H annah. Entre o Passado e o Futuro, $2^{2}$ ed. São Paulo: Perspectiva, 1988. BASTOS, Élide. Oliveira Vianna e a Sociologia no Brasil (Um Debate sobre a Formação do Povo). In: MORAES, J. e BASTOS, Élide. (O rgs.). 0 Pensamento de O liveira Vianna Campinas: Ed. Unicamp, 1993.

BEIRED, José. L. Sob o Signo da Nova O rdem: Intelectuais Autoritários no Brasil e na Argentina. São Paulo: Loyola, 1999. 
BO BBIO, Norberto. Estado, Governo e Sociedade. Rio de Janeiro: Paz e Terra, 1987. BO BBIO, N orberto. Teoria Geral da Política. Rio de Janeiro: Campus, 2000. CARVALHO, José. M. A U topia de O liveira Vianna. In: BASTOS, Élide e M O RAES, João Q . (O rgs.). 0 Pensamento de O liveira Vianna. Campinas: Ed. U nicamp, 1993. CARVALHO, José. M. A Construção da O rdem e Teatro de Sombras. Rio de Janeiro: Ed. UFRJ/Relume-Dumará, 1996.

DIN IZ, Eli \& LIM A, M aria. R. O M odelo Político de O liveira Vianna. Revista Brasileira de Estudos Políticos, n. 30, 1971.FERREIRA, Gabriela. N. Centralização e Descentralização no Império - o debate entre Tavares Bastos e visconde de Uruguai. São Paulo: Editora 34, 1999.

HAYEK, Friedrich. 0 Caminho da Servidão, 5ª ed. Porto Alegre: Instituto Liberal, 1990. HIRSCHMAN, Albert. A Retórica da Intransigência. São Paulo: Companhia das Letras, 1995.

LAMO U NIER, Bolivar. Formação de um Pensamento Político Autoritário na Primeira República: U ma Interpretação. In: FAU STO, Boris. (O rg.). História Geral da Civilização Brasileira: $O$ Brasil Republicano, vol. 9, 3a ed. Rio de Janeiro: Difel, 1985.

MADEIRA, Marcos. Apresentação. In: O LIVEIRA VIANNA, Francisco J. Ensaios Inéditos. Campinas: Ed. U nicamp, 1991.

MERCADANTE, Paulo. A Consciência Conservadora no Brasil, $3^{a}$ ed. Rio de Janeiro: Nova Fronteira, 1980.

M ORAES, João. Q . Ideólogos Autoritários e Teorias sobre o Autoritarismo: uma Síntese Crítica. Filosofia Política, Porto Alegre, v. 3, 1986.

MORAES, João. Q . O liveira Vianna e a Democratização pelo Alto. In: BASTOS, Élide e M O RAES, João Q . (O rgs.). 0 Pensamento de O liveira Vianna. Campinas: Ed. Unicamp, 1993.

O LIVEIRA VIANN A, Francisco J. Ensaios Inéditos. Campinas: Ed. U nicamp, 1991. O LIVEIRA VIANNA, Francisco J. Instituições Políticas Brasileiras, $3^{a}$ ed. 2 vols. Belo Horizonte: Itatiaia, 1974.

O liVeira VIann A, Francisco J. Problemas de Política O bjetiva, $3^{\text {a }}$ ed. Rio de Janeiro: Record Cultural, 1974a.

O LIVEIRA VIANNA, Francisco J. Problemas de O rganização e Problemas de Direção. Rio de Janeiro: José O lympio, 1952.

O LIVEIRA VIANNA, Francisco J. 0 Idealismo da Constituição, $2^{a}$ ed. São Paulo: Companhia Editora Nacional, 1939.

O LIVEIRA VIAN NA, Francisco J. Populações Meridionais do Brasil, vol. 1, $4^{\natural}$ ed. São Paulo: Companhia Editora Nacional, 1938. 
O LIVEIRA VIANNA, Francisco. J. Evolução do Povo no Brasil, $2^{a}$ ed. São Paulo: Companhia Editora Nacional, 1933.

O LIVEIRA VIANNA, Francisco. J. 0 Idealismo da Constituição. Rio de Janeiro: Terra de Sol, 1927.

PAIM , Antônio. O liveira Vianna e o Pensamento Autoritário no Brasil. In: O LIVEIRA VIAN N A, Francisco J. Instituições Políticas Brasileiras, $4^{a}$ ed., vol. 2. Belo Horizonte: Itatiaia, 1987.

PIVA, Luis. G. Ladrilhadores e Semeadores - A Modernização Brasileira no Pensamento Político de Oliveira Vianna, Sérgio Buarque de Holanda, Azevedo Amaral e Nestor Duarte (1920 - 1940). São Paulo: Editora 34, 2000.

RAMOS, Alberto. G. Administração e Estratégia de Desenvolvimento. Rio de Janeiro: Editora da FGV, 1978.

RICOUER, Paul. The Model of the Text: Meaningful Action considered as a Text. In: RABIN OW, Paul and SU LLIVAN, W illiam (Eds.). Interpretive Social Science: a Reader. Berkeley: U niversity of California Press, 1979.

SANTO S, Wandeley G. dos. O rdem Burguesa e Liberalismo Político. São Paulo: Duas Cidades, 1978.

SANTO S, Wanderley. G. Raízes da Imaginação Política Brasileira. Dados, Rio de Janeiro, n. 7, 1970

SARTO RI, Giovanni. A Teoria da Democracia Revisitada, vol. 1. São Paulo: Ática, 1994.

SCHU M PETER, Joseph. Capitalismo, Socialismo, Democracia. Rio de Janeiro: Zahar, 1984

SILVA. Ricardo. Estado autoritário e tecnocracia. Revista de Ciências Humanas, Florianópolis, n. 29, abril, 2001.

THO MPSO N, John. Ideologia e Cultura Moderna. Petrópolis: Vozes, 1995.

THO MPSO N, John. Studies in the Theory of Ideology. Cambridge : Polity Press, 1984.

VIEIRA, Evaldo. Autoritarismo e Corporativismo no Brasil, 2ª ed. São Paulo: Cortez, 1981.

WEBER, Max. Metodologia das Ciências Sociais, vol. 1 Campinas. Ed. da Unicamp, 1992.

ZIZEK, Slavoj. O Espectro da Ideologia. In: ZIZEK, Slavoj. (O rg.). Um Mapa da Ideologia. Rio de Janeiro: Contraponto, 1996. 